LBNL-43704

\title{
Additionality of Emissions Reductions \\ From Clean Development Mechanism Projects: \\ Issues and Options for Project-Level Assessment
}

\author{
Stephen Meyers \\ Energy Analysis Department \\ Environmental Energy Technologies Division \\ Lawrence Berkeley National Laboratory \\ Berkeley, CA
}

July 1999

This work was supported by the U.S. Environmental Protection Agency through the U.S. Department of Energy under Contract No. DE-AC03-76SF00098. 


\section{DISCLAIMER}

This report was prepared as an account of work sponsored by an agency of the United States Government. Neither the United States Government nor any agency thereof, nor any of their employees, make any warranty, express or implied, or assumes any legal liability or responsibility for the accuracy, completeness, or usefulness of any information, apparatus, product, or process disclosed, or represents that its use would not infringe privately owned rights. Reference herein to any specific commercial product, process, or service by trade name, trademark, manufacturer, or otherwise does not necessarily constitute or imply its endorsement, recommendation, or favoring by the United States Government or any agency thereof. The views and opinions of authors expressed herein do not necessarily state or reflect those of the United States Government or any agency thereof. 


\section{DISCLAIMER}

Portions of this document may be illegible in electronic image products. Images are produced from the best available original document. 


\begin{abstract}
The Clean Development Mechanism (CDM), provided for in the Kyoto Protocol, is designed to encourage project activities in developing countries that result in greenhouse gas (GHG) emissions reductions. To receive credit, emissions reductions should be additional to what would occur in the absence of the CDM. Establishing a workable way to judge whether reductions are additional to what would happen otherwise is a vexing challenge. The problems with project-level assessment in the AIJ phase have led to interest in simpler approaches for determining project additionality and baselines. Because a project-level approach takes each case separately, however, it affords greater opportunity than alternative approaches to ensure that emissions reductions are likely additional.

This paper considers improvements to a project-level approach that could reduce the problems that have arisen in the past. Attempting to judge the behavior of actors -- whether a given project or investment would be likely to happen without CDM -- is invariably subjective, but it is possible to base a judgement on a combination of quantitative and qualitative factors, leading to a ranking of the project's probability of additionality. The percentage of the project's verified carbon credits could be scaled accordingly. One way to reduce risks to investors while protecting the environmental integrity of carbon credits would be to pre-certify the behavioral additionality of a project, but use a dynamic baseline for measuring the GHG reductions. This approach would offer a reasonable correspondence between the credits granted to a project and the actual GHG impacts, but the investors would not be held accountable for all of the changes in conditions that might affect "what would occur" in the absence of CDM. The ideas suggested could reduce some of the problems of project-level assessment, but they do not avoid the inescapable subjectivity of judging what would occur in the absence of CDM. Such subjectivity, and its accompanying risk to project investors, may be inevitable if CDM procedures are to achieve an adequate balance between ensuring reasonable integrity of carbon credits and not unduly constrain investment.
\end{abstract}




\section{Introduction}

The Clean Development Mechanism (CDM) is provided for under Article 12 of the Kyoto Protocol, which was agreed at the Third Conference of the Parties to the UN Framework Convention on Climate Change in Japan in 1997. It will enable non-Annex I countries to benefit from project activities in their countries that result in certified greenhouse gas (GHG) emissions reductions. These emission reductions can be purchased by Annex I countries to contribute to their compliance with their emissions limitation obligations under the Protocol. Certified emission reduction units can be created any time beginning in the year 2000 and used to achieve Annex I compliance beginning in 2008.

Article 12.5 of the Kyoto Protocol states that emissions reductions from project activities conducted within the context of the CDM shall be certified on the basis of:

1. Voluntary participation approved by each Party involved,

2. Real, measurable, and long-term mitigation benefits, and

3. Reductions in emissions that are additional to any that would occur in the absence of the certified project activity.

Establishing a workable way to judge whether reductions in emissions are additional to what would happen without the CDM activity is perhaps the most vexing challenge facing the CDM. Assuming that the value of carbon credits sufficiently outweighs the transaction costs of gaining CDM certification, there is an incentive for project sponsors to claim credit for activities that were either already planned, or might take place in the near future if conditions are favorable. Worse, neither host countries nor Annex 1 countries have any incentive (apart from climate protection) to carefully monitor such claims. Without strong oversight from an independent entity, CDM could become a source of considerable "tropical hot air." In this event, CDM would serve primarily as a device for increasing the profitability of investments in developing countries in technologies that are climate-friendly and serve local development objectives. But it would do little to reduce the rising atmospheric concentration of greenhouse gases, since CDM credits purchased by Annex 1 countries would be used as an alternative to domestic emissions reductions.

Ideally, the CDM should provide a reasonable degree of real (additional) emissions reductions without constraining investment in projects. Designing such a solution requires a careful balancing act, however. If the criteria for judging additionality are too lenient, then CDM will mainly produce "tropical hot air." If they are too strict, they will hinder investment in projects, and the flows expected by developing countries will not occur. A difficulty is that the attractiveness of CDM certification very much depends on the value of the carbon credits, which at this point is rather low. It is thus hard to know how strict one can afford to be at the outset.

\section{Alternative Approaches for Judging Project Additionality}

The experience with $\mathrm{JI}$ and AIJ has shown the subjectivity and potential for disagreement in making ad hoc assessments of additionality at a project level. From the perspective of the private sector, one of the main problems with the U.S. Initiative for Joint Implementation has been the 
shifting definition and application of additionality standards. ${ }^{1}$ The USIJI additionality criteria have been criticized for being difficult to evaluate, and not applied in a consistent manner across projects. The result is a high level of risk for private sector companies. Case-by-case evaluation has also led to high transaction costs for both project developers and evaluators.

The problems with project-level evaluation have led to interest in simpler, less burdensome: approaches for determining project additionality and appropriate project baselines. Two main alternative approaches have been suggested for dealing with the additionality criterion in CDM. ${ }^{2}$ One involves establishing quantitative benchmarks at some appropriate level. Benchmarks could be expressed in terms of tons of carbon per unit of output (e.g., $\mathrm{tC} / \mathrm{kWh}$ generated). Any project whose emissions level is below the relevant benchmark would be considered additional, and the benchmark would serve as the baseline for measuring emissions reductions. The benchmark could be based on various criteria (such as "best current practice"), and could be adjustable over time. $^{3}$

A related approach involves creating lists (or matrix) of specific technologies that would be considered as the baseline technologies for different sectors or subsectors in a given country or region for a specified time period. Projects that introduced technologies with GHG emissions lower than the appropriate baseline technology would be considered additional.

Whether the above approaches would be viable in practice is unclear. The process of establishing and updating benchmarks and technology lists for large numbers of sectors and countries could be both costly and time-consuming. Having fewer benchmarks at a higher level of aggregation would make their application more problematic. Perhaps most important, there could be considerable potential for projects that would likely occur anyway to have emissions levels below the benchmark, and thus receive credit for non-additional emissions reductions. For example, all projects with zero carbon emissions would qualify, but many of these projects may be profitable and likely to occur on their own. For renewable energy projects, the ease of gaining CDM carbon credits would tend to steer investment toward those countries in which a particular renewable energy technology is already reasonably financially viable and also provides significant GFIG emissions reduction.

If host country governments have the primary responsibility for creating the benchmarks or technology lists for their country, they would have incentive to set "easy to beat" levels in order to encourage investment. External review by independent experts could discourage establishment of levels that are clearly not appropriate, but there would be much room for governments to use assumptions that lead to generous carbon credits for projects.

Finally, the alternative approaches are hard to square with the language of Article 12.5, which clearly calls for a judgement of what "would occur" (presumably, would "likely" occur) in the

\footnotetext{
${ }^{1}$ L. Jacobson and A. Schumacher, "The Clean Development Mechanism: Private Sector Perspective on Investment," The Business Council for Sustainable Energy, Washington, D.C., Nov. 1998.

${ }^{2}$ K. Baumert, "Understanding Additionality," in Trends and Baselines, J. Goldemberg and W. Reid (eds.), UNDP, New York, 1998. See also TT. Hargrave, N. Helme, and I. Puhl, "Options for Simplifying Baseline Setting for Joint Implementation and Clean Development Mechanism Projects," Center for Clean Air Policy, Washington, DC, Nov. 1998. Another approach that has been put forward involves establishing sectoral baselines.

${ }^{3}$ M. Lazarus, et al. Clean Development Mechanism Baselines: An Evaluation of the Benchmarking Approach, Tellus Institute, Boston, MA, 1999.
} 
absence of the CDM activity. The benchmark and technology list approaches involve establishment of objective standards that would serve as a baseline across a number of specific projects. In principle, such baselines could reflect a judgement of what would likely occur without CDM in various sectors, but it would be hard to capture what would be likely in specific cases. The simpler one makes benchmarks, the less realistic as "predictors of behavior" they will be; the more complex they are, the higher is the cost to establish and update them.

To follow the letter of Article 12.5 is impossible. ${ }^{4}$ Because a project-level approach takes each case separately, it affords greater opportunity to remain true to the spirit of Article 12.5 than the alternatives that have been proposed. Thus, it is worth considering whether a project-level approach could overcome the problems that have arisen with JI and AJJ. Such a consideration is the focus of this paper. I first discuss the meaning of additionality, drawing a distinction between technological and behavioral aspects of a baseline. The following section describes the context for CDM projects, and argues that the determination of additionality for different types of projects calls for use of different methods. The next section outlines methods that may be workable for judging additionality at a project level, while the final section discusses key issues in creating a viable process for such judgement.

\section{The Meaning of Additionality}

Judging the additionality of the emissions reduction associated with a project requires measurement against a baseline that represents what would have happened without the project. A CDM project seeks to bring about use of a technology that provides greater mitigation (and other) benefits compared to the one that would be used otherwise in a given setting. The baseline should incorporate the technology that would be used otherwise, as well as parameters related to how it is used. The difference between emissions associated with the baseline technology and the project technology is usually referred to as "environmental" or "emissions" additionality.

Selecting a baseline technology and pattern of use can be relatively straightforward, or controversial. Judging what the actors involved in or targeted by a CDM project would do in the absence of CDM credits is even more challenging. Suppose, for example, that a CDM project intends to convert a large boiler from coal to natural gas. We need to ask, "Would this conversion have happened anyway?' For a project that seeks to encourage a number of actors to adopt a given mitigation technology, we need to ask, "How many of the actors would have adopted the technology without the incentive offered by the project?"

Some writers have used the term "financial" additionality to refer to the issue of whether investment in a project would take place without the CDM benefits. "Behavioral" additionality is a better term, however, since it the behavior of the actors that is at issue.

\footnotetext{
${ }^{4}$ Paragraph 3 suffers from ambiguous wording. Presumably, the question it calls to consider is, "Without the revenue from carbon credits made possible by CDM, would the investment occur anyway?"

Unfortunately, there is no reference to timing. Should one ask whether the investment would occur now? In the near future? At some time in the future? This issue is considered later in this paper.
} 


\section{Judging Behavioral Additionality of CDM Projects: The Context}

Attempting to judge whether a given project or investment would be likely to happen without CDM is invariably subjective. For investments that are clearly not financially attractive, most observers might agree that they would be rather unlikely to occur, at least in the near future. But unless the potential value of the carbon credits is very high, who would want to make such an investment? The closer an investment is to being attractive without carbon credits, the more difficult it is to judge whether it would take place without CDM.

(Some have argued that the CDM should target those projects that are like "high-hanging fruit" meaning investments that are somewhat attractive but are likely to be passed over. Such a strategy might make some sense if the "low-hanging fruit" was already being picked, but that is generally not the case. It is hardly to a country's advantage to encourage investors to go after the highhanging fruit and leave the low-hanging fruit still on the tree. Given the uncertainty about the value of carbon credits, the private sector is very unlikely to embrace such a strategy, especially in the often risky economic climate of a developing country.)

Different types of projects that may arise in the context of CDM raise different issues with respect to behavioral additionality. A basic distinction concerns who will make the investment. In many cases, the project sponsor(s) intends to invest directly in a given technology at a specific location. Such projects, which generally involve a small number of primary actors, include energy supply projects, some energy efficiency projects, and most forestry projects.

In some cases, the project sponsors seek to encourage other actors to purchase a given technology. Such a project would usually target many actors. It could take the form of a government or utility-sponsored program; government agencies in Annex I countries may provide funds for and obtain credits from CDM projects. A project might also involve marketing of a product by a private enterprise. With time, private firms may see that CDM offers an opportunity to bring climate-friendly products into a given market sooner than they would have done otherwise (or at least to claim such). For example, the prospect of gaining carbon credits might entice a refrigerator manufacturer to begin marketing an energy-efficient model in a given country or region sooner than it had planned, since the value of the credits could allow it to sell the model at a lower price.

In the context of JI and AIJ, the great majority of projects have been ones in which the sponsors were primary investors in the technology, with funds coming from foreign private or public sources. Few projects have targeted technology adoption by many actors.

\section{Projects with Few Actors}

The private sector of Annex 1 countries is expected to be the primary source of funds for the CDM. The level of participation by a firm could range from a simple purchase of carbon credits generated by a project that is conceived, managed and financed by a host country entity, to investment and participation in al joint venture business.

Most CDM projects of this type are likely to be business ventures seeking additional funds. Most are likely to be neither very attractive (in which case they would probably go ahead on their own), nor very unattractive (in which case the host country party is not likely to have much interest). Many potential projects will probably offer good prospects for returning an acceptable level of profits, yet the actors may contend that the project would not go ahead on its own. Indeed, there 
are a variety of reasons why a venture that appears profitable might not go forward. These include a lack of equity capital, difficulty in obtaining affordable or long-term financing, and the perceived risk of the venture, which could result in wanting a higher-than normal rate of return.

One might say that the very seeking of CDM status indicates that a project would not go ahead on its own; otherwise, why would the actors go to the trouble of dealing with CDM procedures and the associated costs and delays? The answer depends on the expected value of the project's carbon credits. The degree to which CDM certification could move a project into the attractive realm depends on the amount of credits that it generates and the amount per credit that an Annex I party is willing to pay.

\section{Projects that Target Many Actors}

For projects that target many actors, a consideration of additionality could look at the likely behavior of the project sponsor(s), or the behavior of the actors that the project seeks to influence.

For a project supported by an Annex 1 government agency, a key issue is whether the project might occur in the context of normal development assistance. (Indeed, a concern among developing countries is that Annex I governments will increasingly channel development assistance funds through CDM, since they can gain credits from so doing.) One would also need to consider whether the host country government might go ahead with a project or program on its own. Assessment of either of these questions would be quite difficult in most instances. In the case of a private sector project, the decision to market a given new product is driven more by economic criteria, but many complex factors enter into the decision, making prediction by outsiders quite challenging.

Rather than trying to assess the behavior of the sponsors, a more viable approach is to consider the behavior of the actors targeted by the project, as discussed below.

\section{Judging Behavioral Additionality of CDM Projects: Practical Methods}

Several criteria are important in considering whether a method for judging additionality would be practical to apply. First, its cost should not be exorbitant. Second, it should be understandable by all parties involved. And third, it should not rely too heavily on subjective bureaucratic judgement.

\section{Projects With Few Actors}

One way to judge the likelihood of a project taking place without CDM is to consider its attractiveness from the perspective of the investors. Such consideration could combine quantitative and qualitative assessment.

A quantitative approach for measuring attractiveness could draw on simple financial/engineering analysis of a project. ${ }^{5}$ One could use country- and sector-specific default values for the typical rate of return on investment (ROI) that would be required for a given type of project. If the

\footnotetext{
${ }^{5}$ Such an approach has been described by Kenneth Chomitz of the World Bank in "Baselines for Greenhouse Gas Reductions: Problems, Precedents, Solutions" (July 1998 draft).
} 
project has a higher projected return than the default rate, one could consider it attractive enough to go ahead without CDM, and it would not be considered additional.

This approach would not necessarily predict the actual behavior of the actors in a specific project. As mentioned earlier, a venture that appears profitable might not go forward for several reasons. In addition, profitability is not the only criterion that a firm might consider in judging whether to invest in a project. A low-profit investment that gains entry into a potentially promising new market may be favored over a higher profit project without such a feature.

A potential problem with conducting independent financial analysis is gaining access to the necessary information, some of which companies may not wish to disclose. If one relies on aggregated information provided by the project sponsors, independent review would be difficult, and there would be more opportunity for cheating. For this approach to be viable, the CDM "secretariat" might need to have the authority to require disclosure of key information as a condition for certifying emissions reductions.

Selection of a default ROI is also problematic. Even within specific economic sectors, the return typically required varies. Some contend that determining a valid minimum return on investment for projects is an impossible task because "each company has different benchmarks for deciding whether a project promises a sufficient return or not; and projects and types of projects have different risks."

One way to deal with uncertainty would be to estimate a reasonable range for the rate of return demanded for investments in specific sectors, and then to judge additionality in terms of probability. If the ROI falls below some minimum threshold, the project is presumed to be additional with $100 \%$ probability. If the ROI falls above some maximum threshold, it is presumed non-additional with $100 \%$ probability. Between the thresholds, the presumed probability of the project's non-adoption is interpolated. To calculate carbon credits, the amount of emission reductions associated with the project would be scaled by the estimated probability of additionality. If the acceptable ROI range for a given sector is $20-40 \%$, for example, a project with an estimated ROI of $30 \%$ /year would receive credit for half of the calculated emissions reductions.

Such "scaling" would reduce the incentive for manipulation of data inherent in a system where additionality is a "yes or no" determination. The setting of minimum and maximum ROI thresholds could be entrusted to advisory panels of experts for each sector (as discussed further below).

Given the problems inherent in relying on a financial evaluation, it may be best to combine it with assessment of qualitative factors that affect investment in a given sector. The combined assessment could lead to a ranking on a scale of 1 to 5 , for example. Such ranking would give a 1 to projects judged to be only marginally additional (meaning there is a good chance the investment would occur without (CDM), and a 5 to projects judged to be clearly additional. The percentage of verified carbon creclits granted to a project would be adjusted accordingly. An example of how the process described above might work is described in Box 1.

\footnotetext{
${ }^{6}$ Rentz, H. Joint implementation and the question of additionality, Energy Policy, Vol. 26, No. 4, 1998.
} 


\section{Box 1 \\ Ranking the Probability of Additionality: \\ An Example}

Project. A $10 \mathrm{MW}$ small hydroelectric power plant that will supply electricity to the grid.

Financial assessment. Based on information provided by the sponsor on projected costs and revenue from sale of electricity, the projected IRR is 20 percent. The national advisory panel for energy sector projects has estimated that a reasonable IRR for small-scale independent power projects is $15-25$ percent. This hydro project is thus judged as having a 50 percent probability of being implemented under "business as usual" conditions.

Assessment of other factors. The national or regional office of the CDM secretariat would take into consideration other factors that affect the sponsor's decision to go ahead with the project. (The sponsor has provided a description of these factors in its application for project registration.) In this case, a key factor is that the sponsor has only a small amount of equity, and is unable to get a loan with a long term. Thus, while the project has an attractive IRR overall, the cash flow in the early years (when a short-term loan needs to be re-paid) is poor. Because the project's profitability is somewhat marginal anyway, the sponsors have difficulty in gaining other equity investors. Based on these considerations, the CDM office judges that the project has a low probability of being implemented.

Combined ranking. Based on the financial assessment and the consideration of other factors, the CDM office gives the project a score of 4 on a 1-5 scale, meaning it is judged to have high probability of not taking place under "business as usual" conditions.

Scaling of carbon credits. Based on the additionality score, the project is eligible to receive 80 percent of the gross verified GHG emissions reduction.

\section{Projects that Target Many Actors}

For this type of project, judging the likelihood of technology adoption by the targeted actors is more viable than judging the likely behavior of the project sponsors, as discussed earlier. One can consider the attractiveness of adoption from the perspective of the actors, as in the preceding section. Unlike the situation with a project with few actors, however, with many actors there is a diversity of applications, as well as a wide range of perspectives among the target group regarding what makes adoption attractive.

Another way of addressing the question is to estimate the share of the targeted actors that might adopt the technology in the absence of the program. In the U.S., "crediting" of energy savings from utility DSM programs has often involved an assessment of how many program participants would likely have adopted the target technology without the incentives offered by the program. The estimated effects from these so-called "free riders" are then subtracted out to derive the energy savings that are attributable to the program, and therefore eligible for "credit". The most commonly applied method (being cheapest and simplest) is direct questioning of a sample of

\footnotetext{
${ }^{7}$ Saxonis, W. 1991. "Free Riders and Other Factors that Affect Net Program Impacts," in E. Hirst and J. Reed, eds., "Handbook of Evaluation of Utility DSM Programs." Oak Ridge National Laboratory.
} 
program participants. Comparing program participants to a control group of nonparticipants is more reliable, but also more costly, and valid control groups can be difficult to find. ${ }^{8}$

For a project that involves marketing of a new product by a company, similar "market assessment" methods could be used. Suppose an appliance manufacturer decides to introduce a more energy-efficient refrigerator in a given country, and to subsidize the price with the revenues from carbon credits in order make it more attractive to buyers. The question to answer is what share of the units sold would have been bought at an unsubsidized price. One difficulty in this case is that the subsidy provided to the customer is likely to be less clear than in the case of a government or utility program. It could be hard for an outside observer to assess to what degree a firm has reduced the price, especially if the product is new to a given market.

\section{Project Additionality: Is a Strict Interpretation Viable?}

Much of the discussion of additionality views the question of whether an investment would likely occur without CDM in a somewhat ambiguous fashion. Whether a project concerns a specific installation or seeks to promote technology adoption by many actors, there is always some chance that the actors eventually would adopt a given technology without the CDM incentive. The longer the time frame one considers, the greater is the likelihood of such adoption. Many factors could make the technology adoption more attractive in the future. These include: (1) reduction of price subsidies or duties and taxes that may discourage adoption, (2) decline in the price of the technology due to technological improvement or market forces such as increased competition, (3) better functioning of financial markets, and (4) higher consumer income levels that reduce the initial cost barrier associated with many mitigation technologies.

Most project sponsors could make a reasonable argument that CDM caused a specific installation to take place sooner rather than later, or caused targeted actors to adopt the technology sooner rather than later. Strictly speaking, the associated emissions reduction would not be additional in any year in which the technology would have been in use anyway.

Trying to estimate when a given project or investment would be likely to occur on its own is a major challenge. Take the example of a boiler fuel conversion project. If the CDM secretariat were certifying the behavioral additionality prior to project initiation, it would need to judge when the project would likely occur without CDM. Based on current projection of future conditions, experts might predict that it would take place in around five years without CDM. Thus, the CDM project would provide additional emissions reductions in years 1 through 5 , but not after that, so it would receive credits only for those years. If the determination of behavioral additionality took place after the project was underway, the CDM secretariat might decide after five years that such boiler conversions had become common, and the project would likely occur without CDM. Thus, the project would not be given credit for GHG reductions in future years.

Although a case can be made that accounting for additionality in this way is necessary if the emissions reductions granted to projects are to be "real," the difficulty and subjectivity of making the required estimates is rather obvious. Such determination would increase the developer's risk considerably, and the process could be very contentious.

\footnotetext{
${ }^{8}$ For further discussion of methods for estimating "free riders," see E. Vine and J. Sathaye, 1999. Guidelines for the Monitoring, Evaluation, Reporting, Verification, and Certification of Energy-Efficiency Projects for Climate Change Mitigation. LBNL-41543. Berkeley, CA: Lawrence Berkeley National Laboratory.
} 


\section{Making the Process Operational}

The preceding section considered how behavioral additionality might be assessed at a project level. This section considers when in the CDM project process a determination of additionality might take place, who might make such assessment, and how costly the process might be.

\section{When Should Additionality be Judged?}

Determination of the behavioral additionality of a project could take place prior to the actual initiation of a project, or as part of an ex post evaluation to verify the project's claimed emissions reductions. The language of Paragraph 3 in Article 12.5 seems to imply a prior assessment. "Precertification" of behavioral additionality prior to initiation would reduce the risk for project developers. Judging behavioral additionality after the project is underway would result in a more accurate determination and thus a better assessment of the "real" mitigation benefits of the project, but would present greater risk for project investors.

The determination of behavioral additionality need not take place at the same time as assessment of the reasonableness of a project's technology baseline. One way to reduce risks to project investors while protecting the environmental integrity of carbon credits would be to pre-certify the behavioral additionality of a project, but use a dynamic (changing over time) baseline for measuring the greenhouse gas reductions. ${ }^{9}$ With this approach, there would be a reasonable correspondence between the credits granted to a project and the actual GHG impacts, but the investors would not be held accountable for all of the changes in conditions that might affect "what would occur" in the absence of CDM. Box 2 provides an example of this approach.

\section{Box 2 \\ Pre-Certification of Behavioral Additionality Combined with Dynamic Certification of Emissions Reduction: An Example}

Project. A $10 \mathrm{MW}$ small hydroelectric power plant that will supply electricity to the grid.

Pre-Certification of Additionality: In the application for project registration, the sponsor would explain why the project would be unlikely to occur without the CDM benefits, and provide appropriate financial information. The CDM office would conduct an assessment, consult with appropriate experts, and give the project a ranking according to the probability of its taking place without CDM. The developers could then proceed with the project knowing that the question of behavioral additionality would not be revisited.

Dynamic Certification of Emissions Reduction. The certification of carbon credits would occur as the project proceeds and the sponsor submits claims for credits (perhaps on an annual basis). An appropriate technology baseline for this project would be the electricity generation that would have occurred in the absence of the project. The avoided carbon emissions from the power grid could be calculated annually with reference to an official estimate for the relevant electricity supply system.

\footnotetext{
${ }^{9}$ An approach for establishing official baselines for a national electricity system is described in: S. Meyers, Establishing a Power Sector Baseline for CDM Projects: A Proposed Approach, Lawrence Berkeley National Laboratory, 1999 (draft).
} 
Pre-certification of behavioral additionality could also be used for projects that target technology adoption by many actors. The sponsor's estimate of the percentage of expected "free riders" (whether in a government or utility program or a private-sector product marketing activity) could be reviewed by the CDM office and, if approved, would be used for the lifetime of the project. Thus, if conditions change such that more actors than expected would probably adopt the target technology without the CDM incentive (for example, increase in electricity prices would make efficient devices more attractive to consumers), the project sponsors would not bear the risk that the "free rider" percentage would be revisited.

\section{Who Should Judge Behavioral Additionality?}

The precise manner in which the CDM will operate is still to be determined, but presumably the process of verification of project developers' claims and certification of carbon credits will be the responsibility of some entity operating under the authority of the CDM Executive Board. Some of the necessary activities might be handled by private sector specialists who would have expertise for particular countries or regions and have the capability to conduct evaluation of project impacts.

A legitimate objection to project-level determination is the high degree of discretion left to a bureaucratic organization. The combination of bureaucratic discretion and the inherent subjectivity involved in establishing additionality makes potential project developers uncomfortable. ${ }^{10}$ One approach that would reduce the power of the certifying entity would be to set up advisory panels with expertise in particular areas, such as energy supply, energy efficiency, and forestry. The certifying entity would consult with the appropriate panel for a given project, and could be encouraged to give strong weight to its recommendation. The panels could operate at a national or regional level and consist of respected experts from universities and the private sector, perhaps drawing on the IPCC network of experts. A possible drawback of this approach is that the consultation process could be rather time-consuming.

\section{Cost of Project-Level Assessment}

One of the main objections to project-level assessment of baselines and additionality is the cost involved for both project developers and the responsible organization. Whether the overall cost would be more than that involved in establishing a viable system of benchmarks or technology lists is unclear, but there is no denying that a responsible process of project-level evaluation would entail costs. Reliance on advisory panels could streamline the process somewhat, but probably the experts would need to be paid for their work.

The cost of conducting project-level evaluation does not scale proportionally with the size of a project. Thus, the cost as a percentage of the total value of carbon credits earned can be much higher for a small project than for a large project (considering size in terms of the expected GHG impact). It might make sense to conduct rigorous project-level evaluation only for projects whose expected impact is above a certain magnitude. On the other hand, this could encourage cheating with small projects.

\footnotetext{
${ }^{10}$ B. Stigson, "Attracting Northern Private Sector Investment for Greenhouse Gas Reduction in the South," in J. Goldemberg (ed.), Issues and Options: The Clean Development Mechanism, UNDP, 1998.
} 


\section{Conclusion}

Any method for judging the "behavioral" additionality of CDM projects will need to strike a balance between competing demands. Project-level determination is likely to provide a more realistic assessment of GHG impacts, thereby protecting the integrity of CDM carbon credits, but runs the risk of deterring potential investors concerned about the degree of bureaucratic discretion and uncertainty involved.

The project-level approaches for judging behavioral additionality described in this paper do ultimately rest on a bureaucratic determination. Establishing a quantitative framework based on financial evaluation would let project developers know what the criteria are and how they will be applied, but the final decision would still require a significant degree of subjective judgement. Scaling of carbon credits based on the judged probability of additionality would reduce the risk to developers, as would pre-certification of additionality. Finally, establishment of advisory panels would both enhance the quality of the judgement and ease the task of the CDM "secretariat".

Since the cost of conducting project-level evaluation could be substantial, it may be advisable to create separate tracks for large and small projects, with only large projects required to submit to rigorous project-level evaluation. This "two-track" approach would reduce the work load of the CDM "secretariat". To discourage cheating among small projects, a system in which a small percentage of such projects were randomly audited could be established.

This report has suggested several ideas that would reduce some of the problems that have been associated with project-level assessment under the AIJ pilot phase, but none of these get around the inescapable subjectivity of judging what would occur in the absence of CDM. Even a wellfunctioning project-level approach, done rigorously, would pose a barrier to investment in projects by the private sector. The question is whether other approaches are likely to be any better at achieving an adequate balance between ensuring a reasonable degree of integrity of CDM carbon credits and not unduly constraining investment.

It seems advisable to begin operating the CDM (perhaps in an Interim Phase) using project-level assessment. Even if the COP elects to establish a system of benchmarks or technology lists as an alternative to project-level assessment, doing so is likely to take considerable time and expense. In the meantime, one could assess the extent to which project-level evaluation does in fact act as a barrier to investment, and perhaps make adjustments so that it works more effectively. If in the beginning the number of projects is not so great, that might be preferable to a system that allows a flood of projects that may have occurred anyway, thus undermining the integrity of the CDM as a tool for climate protection. 